\title{
Assessing regulatory performance: The case of the Namibian electricity supply industry
}

\section{Joseph Kapika}

\author{
Anton Eberhard \\ Graduate School of Business, University of Cape Town
}

\begin{abstract}
The power sector reforms that commenced in the 1990 s led to the establishment of independent electricity regulators in more than twenty countries across Africa. The main purpose for these institutions was to create greater transparency in tariff setting and provide increased certainty for investors. At the same time regulators are charged with the protection of the interests of current and future consumers of electricity. During the initial stages of reform it was the expectation that the state owned incumbents that were traditionally vertically integrated would be unbundled and privatised. In practice there have been very few privatisations and what have emerged are hybrid markets where stateowned utilities remain dominant with independent power producers on the margin. In these markets regulation is a complex melting pot of incentivising the performance of state-owned utilities, attraction of private sector investment especially to fill gaps in generation capacity and making sensitive pricing decisions. Recognising that regulation is beginning to establish a track record, the African Electricity Regulator Peer Review and Learning Network, an initiative of the University of Cape Town, Graduate School of Business provides an opportunity for high level learning through the assessment of regulatory performance. We detail an assessment of regulation in Namibia where we find prices transitioning to cost reflectivity but question the sustainability of current arrangements in the distribution of electricity and the country's long-term generation adequacy.
\end{abstract}

Keywords: regulatory performance, regulatory impact, regulatory governance, regulatory substance, peer reviews, experiential learning

\section{Introduction}

\subsection{The peer learning network}

This paper draws on the work of the African Electricity Regulator Peer Review and Learning Network (Peer Learning Network), an initiative coordinated by the Management Programme in Infrastructure Reform and Regulation (MIR) at the University of Cape Town's (UCT) Graduate School of Business (GSB).

The Network comprises the Chief Executive Officers of the electricity regulators in Ghana, Kenya, Namibia, Tanzania, Uganda and Zambia (the members) who assess regulatory performance in each others' countries. This is done through structured and comprehensive peer reviews that also provide opportunities for deep experiential learning by the network members. It is expected that the lessons learnt will enhance leadership and management capability amongst senior regulators in Africa, and lead to increased credibility, legitima$c y$, transparency and robustness in their decisions.

The first peer review was conducted in Windhoek, Namibia from 20 to 24 October 2008 and is the subject of this paper.

\subsection{Approach}

Over a one week period, five of the members of the Peer Learning Network evaluate, on site, the regulatory system in the country of the sixth member. Interviews are undertaken with all relevant stakeholders ranging from the responsible minister, regulatory commissioners (board members), utilities, investors, consumer groups, non-governmental organisations and journalists. During the interviews, the stakeholders are invited to give their views on their experience with and performance of the electricity regulator and the electricity sector as a whole. This is followed by in-depth interrogation of regulator staff on the processes and outcomes of regulatory decisions. 
The method of evaluation is adapted from Brown, Stern, et al.(2006) where the regulatory system is defined as 'the combination of institutions, laws, and processes that give government control over the operating and investment decisions of enterprises that supply infrastructure services.' Brown, Stern et al., (2006) observe that: 'any regulatory system has two important dimensions: regulatory governance and regulatory substance.' Regulatory governance, also referred to as the 'how' of regulation, is 'defined by the laws, processes, and procedures that determine the enterprises, actions, and parameters that are regulated, the government entities that make the regulatory decisions, and the resources and information that are available to them' (Stern, 2009).

Regulatory substance is the 'what', or content, of regulation referring to core regulatory actions and decisions in relation to licensing (i.e. market access), tariff setting and supply and service and standards. The desired outcome of the interaction between regulatory governance and regulatory substance, regulatory impact, can be distilled into four main themes: cost effective pricing; reliable and quality infrastructure (electricity) service; sector financial and economic viability; and the timely attraction of new investment. Based on the foregoing, the regulatory system can be depicted as shown in Figure 1.

\section{A framework for assessing regulatory performance \\ 2.1 Regulatory impact}

Effective regulatory systems create a more predictable and less risky environment for private investment and 'is a means to an end' (Stern \& Holder 1999). That end should be seen in the context of regulatory impact.

As shown in Figure 1, regulatory impact is influenced by the regulatory governance arrangements and the content of regulation (regulatory sub- stance). Consistent with the desired outcomes of regulation enumerated in Section 1.2 i.e. cost-effective pricing, reliable and quality infrastructure service, financially viable utilities and the attraction of new investment, Stern (2009) observes that the 'key objective of economic regulation of infrastructure industries is to ensure the continuous supply, over the long-term, of unspecified infrastructure services of defined quality at the minimum necessary cost (and prices) to the population and industry of the country.' It is within this context that regulatory performance should be evaluated.

\subsection{Regulatory performance}

The determination of regulatory performance is however not a simple undertaking. As Brown, Stern et al (2006) state, "it is virtually impossible in a single-country case study to calculate the separate effect of a new regulatory system on overall sector performance.' This difficulty arises from the fact that regulatory reform tends to be part of a wider package of measures that may include restructuring, commercialisation, private sector participation etc. Faced with this limitation, our approach to understanding regulatory performance is two-fold; firstly, we gather data based on the desired sector outcomes and secondly, an interrogation of whether the specific elements of regulatory governance and regulatory substance in Namibia help or hinder sector performance is made.

\subsection{Regulatory governance}

Regulatory governance is "the institutional and legal design of the regulatory system and is the framework in which decisions are made' (Brown, Stern et al,. 2006). Newberry (1977) presents the regulatory problem as the need to 'agree a regulatory compact which assures investors that their sunk capital will be adequately rewarded, and they will be protected from populist pressure to reduce prices to

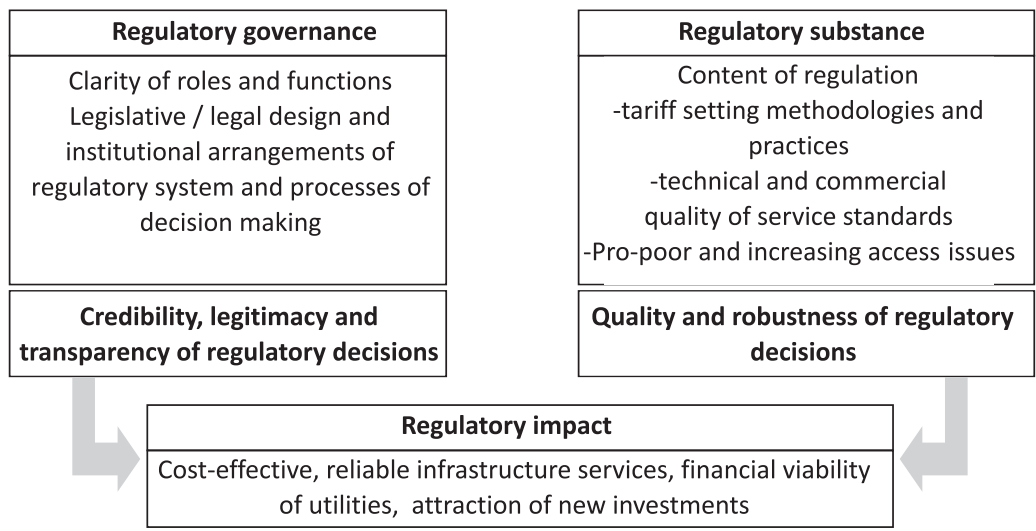

Figure 1: The regulatory system 


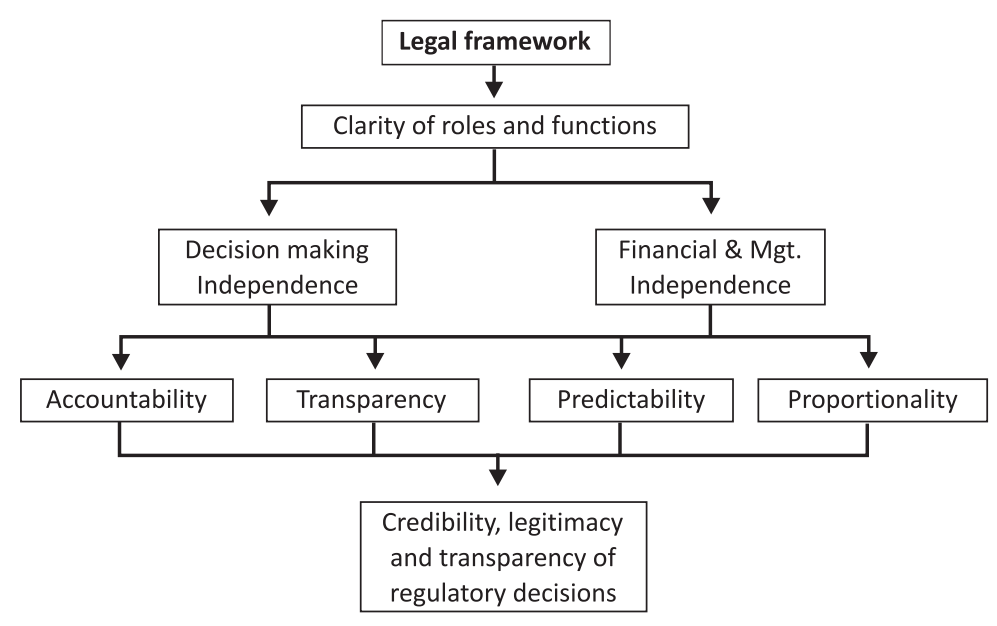

Figure 2: Regulatory governance

avoidable cost.' Such a regulatory compact should create more certainty and in effect reduce the amount of decision-making discretion available to the regulator, i.e. it should reduce arbitrary decision-making. Levy and Spiller (1994) define regulatory governance as being the mechanisms that societies use to constrain regulatory discretion and to resolve conflicts that arise in relation to these constraints'. They further state that performance (in the sense of sustaining private sector investment) can be satisfactory, provided three complimentary mechanisms restraining arbitrary administrative action are in place, namely: '(a) substantive restraints on the discretion of the regulator, (b) formal or informal constraints on changing the regulatory system, and (c) institutions that enforce the above formal-substantive or procedural-constraints'. This might imply that full regulatory commitment is exhibited through regulators having no discretion. But as Stern and Cubbin (2005) observe: 'in practice, it is virtually impossible for regulatory agencies to avoid interpretation of their objectives and to avoid discretion. The issue is then how to establish governance procedures that allow for the inevitability and desirability of a non-trivial degree of bounded and accountable discretion.' To achieve this, Stern and Holder (1999) contend that governance arrangements should be such that they ensure transparency and predictability, two attributes that are anchored on accountability. They present accountability as comprising two aspects; formal and informal. Formal accountability refers to the formal legal basis in which the regulator operates, effectively in the tradition of the call for restraint presented by Levy and Spiller (1944) whereas informal accountability is the degree to which the regulatory process "encourages debate and open discussion; involves all relevant parties; leads to justification by the regulator of decisions and methodologies; and generally leads to a clear understanding of the "rules of the game"" (Stern, 1977).

From the foregoing regulatory governance can be depicted as shown in Figure 2 which provides the basis for the Peer Learning Network's evaluation of this dimension of the regulatory system.

\subsection{Regulatory substance}

Brown, Stern et al. (2006) define regulatory substance as the content of regulation, the actual decisions, whether explicit or implicit, made by the regulatory entity. The network and natural monopoly characteristics of many infrastructure industries, such as electricity transmission and distribution, mean that economic rent may be extracted by operators at the expense of consumers, and that economic regulation is necessary. There is a large body of literature on economic regulation and tariff setting. It is not intended that a review of various pricing methodologies is made here, suffice to state that regulators have various well tested means at their disposal to determine tariff levels and tariff structures.

Regulatory substance is primarily about pricing decisions. It is also about determining market access, through licences. A further dimension is the development and enforcement of technical and commercial quality standards, and resolution of disputes between utility and consumer and amongst utilities. Other substantive issues that are of special importance in Africa are pro-poor measures that facilitate access to, and affordability of, electricity services. Figure 3 depicts regulatory substance.

\section{The Namibian electricity industry 3.1 Policy and regulation}

Policy direction for the Namibian electricity industry is provided by the Ministry of Mines and Energy. Following the enactment of the Electricity Act in 


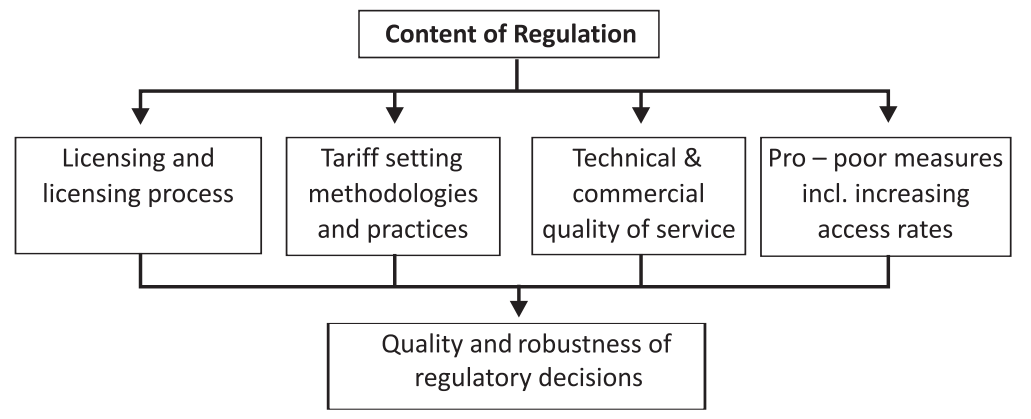

Figure 3: Regulatory substance

2000, an independent regulator for the industry, the Electricity Control Board (ECB), was established. In 2007 the Electricity Act was amended, making provision for private participation in the sector.

\subsection{Industry structure}

At the time of the peer review the structure of the Namibian electricity industry was in transition and is shown in Figure 4.

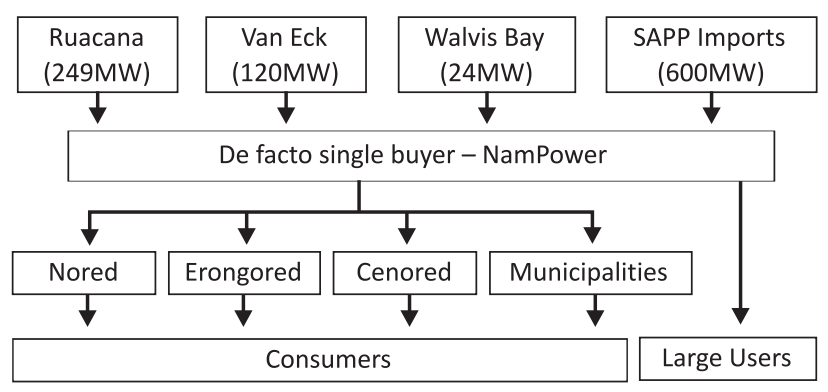

Figure 4: Existing structure of Namibia electricity industry

Matters that remain outstanding with respect to the structure include the location of the single buyer function, currently retained de facto by NamPower, and its roles, obligations and governance structure, particularly as they relate to the need to assure prospective Independent Power Producer (IPP) investors of a 'level playing field'. In addition, whether IPPs should exclusively trade with the single - buyer, or have bilateral access to local and international parties, has been a matter of debate.

In distribution, the formation of two REDs one covering the area served by the Windhoek Municipality, the other in the south of the country, remains outstanding. The proliferation of municipal authorities that are to be augmented in the formation of the two outstanding REDs coupled with the problematic local authority surcharge present sizeable challenges in reaching the expected end state structure of the industry.

\section{Understanding regulatory performance in Namibia \\ 4.1 Key regulatory issues}

The Namibian ESI faces four main regulatory issues. Firstly, as is the case in the rest of subSaharan Africa (Eberhard, Foster et al., 2008), enduse electricity tariffs do not reflect the full cost of generation, transmission, distribution and supply. Secondly, access to electricity is low. 2001 figures show that while for urban areas access was an enviable $67.6 \%^{1}$ (less than a quarter of households in sub-Saharan Africa have access), rural access remained at a low $9.5 \%$ resulting in an overall country access rate of $32 \%$. Thirdly, peak demand at $533 \mathrm{MW}^{2}$ (which had grown at an annual average rate of $5.3 \%$ over the period $1998-2008$, Figure 5); outstrips the country's installed capacity of $393 \mathrm{MW}$ and is forecast to almost double over the next ten years (NamPower, 2009). This has led to Namibia being increasingly dependent on electricity imports from its neighbours in the Southern African region as shown in Figure 6.

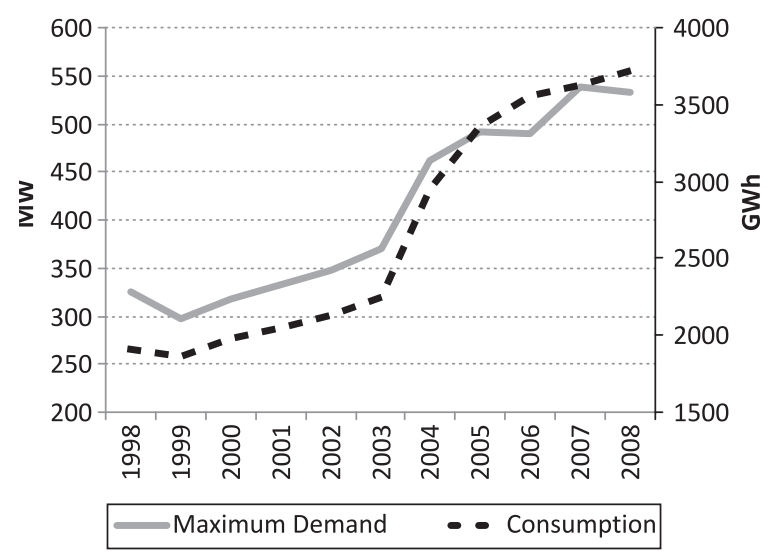

Figure 5: Namibia demand and consumption

However, the region as a whole is experiencing a generation deficit and the Southern African Power Pool (SAPP) forecasts that this shall be the case until 2013 at the earliest (Southern African Power Pool, 2009). As a result, the Government of Namibia $(\mathrm{GoN})$ is keen that new indigenous generation 
capacity is built. While a pipeline of new generation projects has existed for some time, none have yet been realised. The earliest that any new generation is expected to come on stream is now 2012 when the fourth $92 \mathrm{MW}$ unit at Ruacana Power station enters commercial operation. The flagship Kudu gas-to-power project which is crucial for the country's goal of self sufficiency in generation has faced delay and due to conceptual design changes has now been resized from its initial $800 \mathrm{MW}$ to 500 MW and might only be commissioned in 2014 .

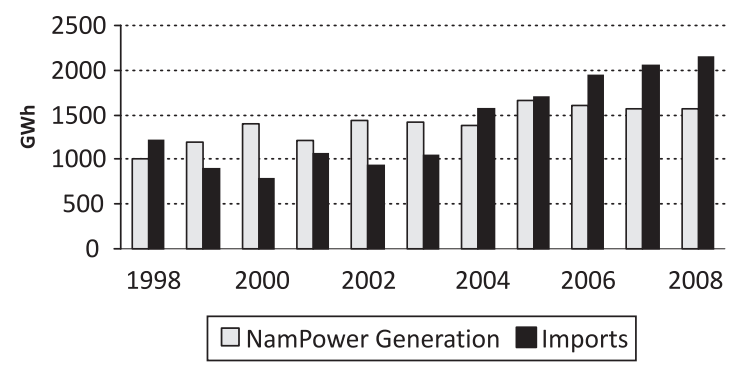

Figure 6: Indigenous generation vs imports

The fourth issue is the number of small and nonviable electricity distributors. For a country with a population of two million and with an access rate of $32 \%$, it is somewhat surprising that there are 22 entities licensed to distribute electricity. This places an inordinate amount of required regulatory effort on the industry regulator, the Electricity Control Board (ECB). In addition, municipal-owned electricity distributors electricity are permitted to a discretionary tax known as the Local Authority Surcharge (LAS), which adds considerably to the cost of electricity.

\subsection{Regulatory governance}

While the mere establishment of an independent regulatory agency does to some extent signal regulatory commitment, the achievement of desired outcomes is dependent on the design of the regulatory system. A key finding for Namibia was that although the Electricity Act was unambiguous in its allocation of roles and responsibilities, quite a significant degree of final decision-making authority that would ordinarily reside with the regulator had been retained by the Minister. For example, the Minister, rather than the regulator, approves licences and regulations, thus compromising the independence of the regulator. ECB officials that were interviewed did however not find these clauses to be problematic but rather claimed that the arrangement gave rise to a degree of political legitimacy and had in fact worked well so far. The reason for this appeared to be more on account of personnel as opposed to the systems in place. For this reason it was questionable whether this good working relationship would be sustained over time.
Procedurally it was unclear how the Minister would make the relevant regulatory decisions and hence the required degree of bounded and accountable discretion, referred to in section 2.3, which is absent. In any case, given that the ECB has final decision making authority over what is ostensibly the most contentious of regulatory matters, tariffs, it was surprising that the remaining regulatory responsibilities had been left to Ministerial discretion.

Formal accountability requires that there is a mechanism through which regulatory decisions can be appealed. While parties to an ECB decision had the inalienable right to approach the courts of law for judicial review, it was found that there was no internal procedure that could be used to appeal to the ECB directly. The regulator had noted this anomaly and was in the process of developing a procedure.

Effective regulatory governance should 'encourage debate and open discussion' (Stern, 1997) as part of its informal accountability attributes. An avenue that regulators regularly use to achieve this is the holding of public hearings on key issues such as for tariff applications. This was however not the case in Namibia. Public hearings could lead to greater public awareness of the regulatory process and engender a better understanding of regulation including matters such as the methodologies employed for tariff setting. The absence of public hearings in Namibia could in part explain why there was no organised lobby that, in a sustained manner, made representations before the regulator on behalf of general electricity consuming public.

\subsection{Regulatory substance}

\subsubsection{Cost-effective pricing}

Namibia's Energy Policy (1998) sets out the following guiding principle for the setting of tariffs:

- Sound economic principles;

- Cost reflectivity (as far as possible);

- Should reflect long run marginal costs of supply; and

- Grant existing and potential industry participants a level playing field.

Even though NamPower is a vertically integrated utility, tariffs for generation, transmission and distribution in Namibia are determined separately. For generation, the ECB uses an inefficient import parity pricing (IPP) regime that prices local generation at the cost of imported electricity. The rationale for this is the country's high dependence on electricity imports especially from South Africa. However, the effect of this regime is to excessively reward the low cost to the Ruacana hydro plant. The regulator was of the view that these windfall gains can then be used to subsidise the higher cost coal-fired Van Eck power station and the Paratus diesel power plant. In recent years, primary energy costs have risen significantly (e.g. NamPower coal costs rose $378 \%$ 
between 2003 and 2008 - Figure 7) and the import parity derived average generation price has been insufficient to meet the cost of increased generation at Nampower's two thermal plants. As a result, the ECB has suspended the import parity regime and instead takes into account actual fuel costs. In future it is intended that the Revenue Requirement approach, which is already in use for transmission and distribution, shall be adopted for the generation sector.

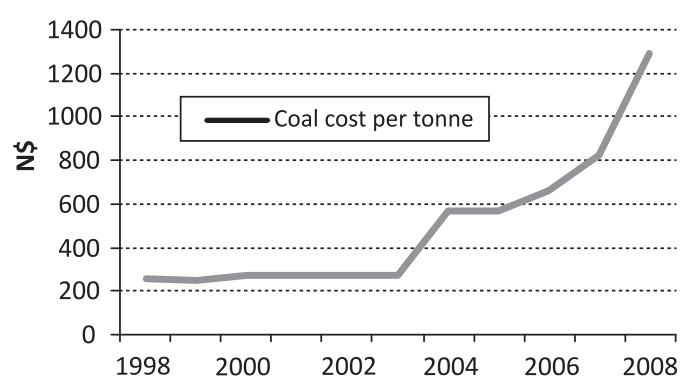

Figure 7: NamPower coal cost

Cost reflectivity

Theoretically the Revenue Requirement calculation - based on rate of return on assets plus depreciation and operating and maintenance costs, allows for full cost recovery. However, this has yet to be achieved. The Namibian government has a stated objective of reaching cost reflectivity in bulk tariffs by 2010/11, but progress has been difficult, mainly because of the increase in fuel prices (Figure 8).

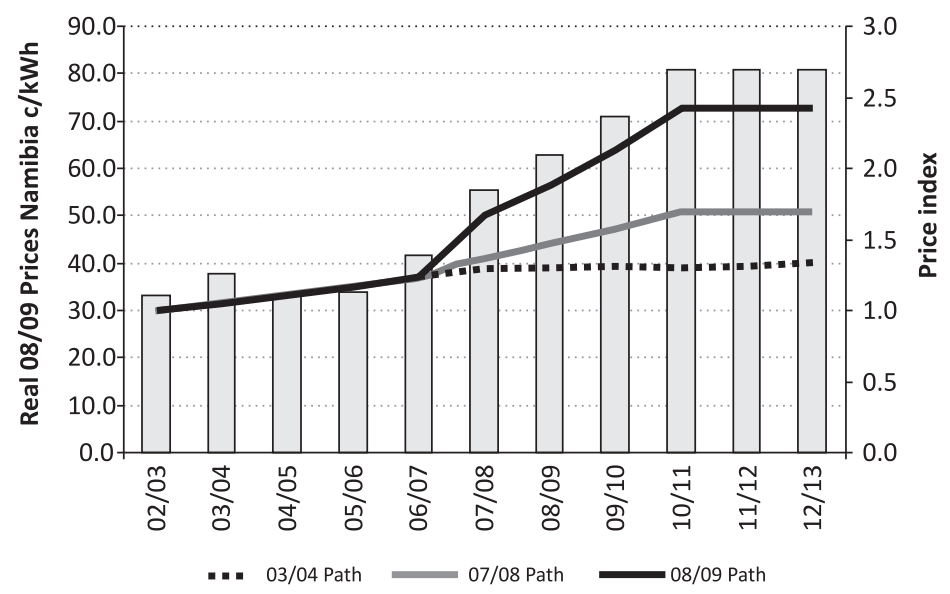

Figure 8: Path to cost reflectivity (N\$) Source: Electricity Control Board
Although tariffs are yet to reach cost reflective levels, it is commendable that over the period 2002 to 2007, NamPower's average price had not been eroded by inflation and had in fact risen in real terms, as shown in Table 1 . The effect of this is that consumers will be shielded from excessive tariff increases as the government's policy of cost reflectivity is implemented.

\section{Asset valuation}

A progressive feature of the economic regulatory methodology employed in Namibia, is its use of current or replacement asset values when determining the rate of return in its revenue requirement calculation. Most countries in the region rely on historical, depreciated asset values. In conte

xts of high inflation, with long intervals between investments, this can lead to average prices well below those required to support new investment. Namibia's use of replacement values, implies that prices will rise to close to long-term marginal costs and hence be at levels sufficient to attract new IPP investments.

\section{Efficiency incentives}

One of the disadvantages of rate-of-return, or cost-of-service regulation is that it provides few incentives for operators to reduce costs (see Averch and Johnson (1962)). The ECB was aware of this deficiency and for the distribution sector has capped non-technical losses at a stringent $1.25 \%$ of total revenue, or at the level for the previous year whichever was lower. For technical losses these were capped in a range of $10-15 \%$ depending on nature and location of the particular distributor. The ECB did however treat requested maintenance expenses favourably during tariff revisions.

It is also noteworthy that for a country with a population of just over 2 million, the ECB approves 32 distribution tariffs of varying structures. This places an inordinate amount of work on the regulator and also presents a challenge for performance monitoring and benchmarking. This challenge is not eased by the distortionary impact of the discretionary local authority surcharge, which varied from $\mathrm{N} c 9.19 / \mathrm{kWh}$ to Nc56.98/kWh in $2007 / 08$ across the fourteen municipalities that apply it as shown in Figure 9.

Table 1: NamPower average price

\begin{tabular}{lcccccc}
\hline & 2002 & 2003 & 2004 & 2005 & 2006 & 2007 \\
\hline Average price per unit $(\mathrm{N} \$$-cents $/ \mathrm{kWh})$ & 21.56 & 27.63 & 30.11 & 33.77 & 34.71 & 38.38 \\
\hline Average price per unit $(\mathrm{US} \$$-cents $/ \mathrm{kWh})$ & 2.05 & 3.67 & 4.67 & 5.27 & 5.04 & 5.34 \\
\hline Average annual price increase $(\%)$ & $\mathrm{n} / \mathrm{a}$ & 28.2 & 9.0 & 12.2 & 2.8 & 10.6 \\
\hline Average annual inflation $(\%)$ & 11.4 & 7.1 & 4.2 & 2.3 & 5.1 & 6.7 \\
\hline
\end{tabular}




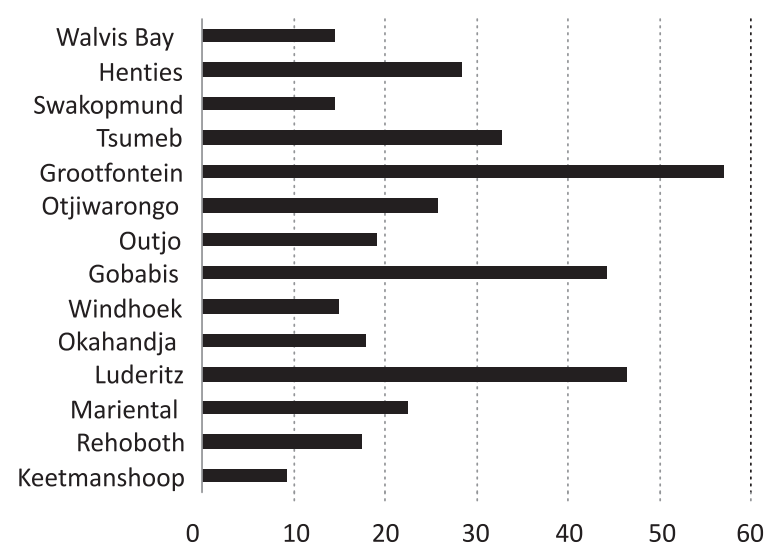

Figure 9: Local authority surcharge ( $\mathrm{N} \phi / \mathrm{kWh})$

\subsubsection{Adequacy and security of supply and the attraction of new investment}

Although the number of consumer groups met in Namibia was by no means representative, there was general contentment with the existing level of electricity quality and reliability. However, future reliability of electricity supplies was at risk since the biggest concern for Namibia remained the looming shortages of electricity supplies as a result of the reduced availability of electricity imports, the absence of IPP investments, increased economic activity and the forecast demand for electricity in the country.

The peer review made five recommendations aimed at enhancing security and reliability of supply. Firstly, it was noteworthy that there was no electricity security supply standard for Namibia. Such a standard if based on an agreed Loss of Load Expectation (LOLE) could introduce more objectivity in the determination of the country's reserve margin, import requirements and the opportune time at which to increase generation and transmission capacities. Secondly, responsibility for monitoring and reporting on this security standard needed to be allocated to the regulator. Thirdly, there appeared to be uncertainty on where the responsibility for the National Integrated Resource Plan (NIRP) lay. During the peer review it was found that while NamPower was undertaking an NIRP, this process had not been recognised by the ECB who intended to undertake a separate planning process. Clearly such duplication was not the most optimum use of otherwise scarce resources. With the attendant need of attracting new generation into the sector, clarification of this responsibility would only aid the process. Lastly, it was noted that most expressions of interest in new build opportunities that were received were unsolicited.

The peer review recommended that international competitive bedding processes be initiated in time to meet the supply requirement indicated in the NIRP. Criteria and processes also needed to be developed for assessing unsolicited bids.

\subsubsection{Financial viability of utilities}

NamPower, the state owned vertically integrated utility and dominant player in Namibia's electricity industry remains a financially viable entity and has been profitable over the last 10 years (Figure 10).

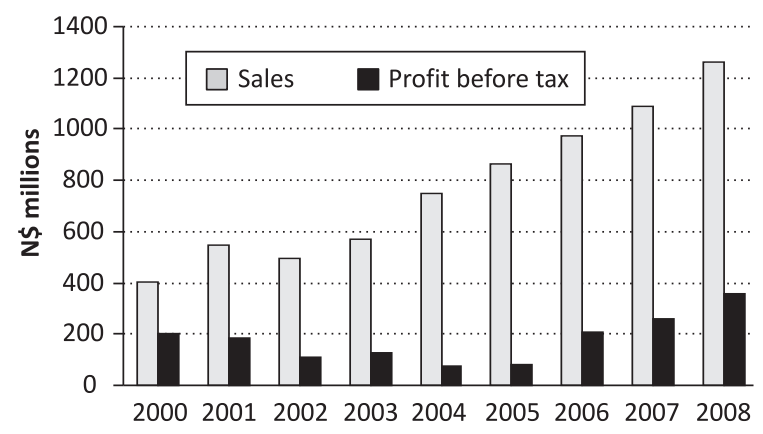

Figure 10: NamPower financial performance

This is in part due to the ECB's commitment to cost reflectivity. More recently, government's $\mathrm{N} \$ 1$ Billion recapitalisation programme $(\mathrm{N} \$ 250$ million in 2007 and 2008 respectively with the balance expected in 2009) has significantly aided NamPower's financial health. In addition, government has approved an annual grant of $\mathrm{N} \$ 120 \mathrm{mil}-$ lion to support the running of expensive thermal generation to ensure security of supply over the period 2008 to 2010. Consequently, on account of these and other factors such as Namibia's (the country) own sovereign rating, rating company Fitch in March 2009 reaffirmed NamPower's BBBinvestment-grade rating. Interestingly, in its assessment of NamPower's operating environment the rating agency makes the following comment: 'The regulator continues to make progress towards bringing regulation more into line with developed market standards' (Fitch, 2009).

In the distribution sector however, challenges remain. A 2006 benchmarking exercise revealed that all the REDs had failed to perform satisfactorily against set benchmarks, with the best performing having only been satisfactory in three of the specified nine specified performance measures shown in Table 2. In interviews with the Chief Executive Officers of two of the REDs, it was revealed that at current tariff levels there was insufficient revenue being generated to earn an adequate rate of return or to fund the depreciation expense. While no evidence was presented to support this assertion, the ECB's own admission that tariffs were at below cost levels lent it credence. It would however, appear that there was also need for internal efficiency improvements within REDs to lower costs. 
Table 2: Key performance indicators

\begin{tabular}{lc}
\hline Performance indicators & Benchmark \\
\hline Financial & $\geq 4 \%$ \\
Return on revalued assets & $\geq 17 \%$ \\
Operating margin & \\
Current ratio & $\geq 1$ \\
Quick ratio & \\
Liquidity & $\geq 90$ \\
\hline Technical & \\
Energy conversion efficiency & $\leq 51$ \\
\hline Commercial & $\leq 30 \%$ \\
Debtor days & $<0.3 \%$ \\
Operating cost / sales & \\
Bad debts & $>300$ \\
\hline Efficiency & $\geq 6000 \mathrm{kWh}$ \\
Customers / employee & \\
Energy sold / employee &
\end{tabular}

Pro-poor initiatives

A special challenge in a country such as Namibia is the need to widen access to electricity services. For a country with an overall access rate of $32 \%$ of which rural access was $9.5 \%$, it was surprising that the regulator did not play an active role in this area. This could be through tariff structures that target the poor, incentivising the extension of the grid by utilities or encouraging the development of off-grid electricity supplies for rural communities.

The peer review found that the only structured initiative for rural electrification was the annual grants disbursed to distributors from central government, which were in themselves insufficient to meet the electrification targets set out in the National Development Plan. Separately, NamPower also provided a subsidy for rural electrification. Interestingly, interviews with the $\mathrm{ECB}$ revealed that this subsidy was not recovered in the tariff and that instead 'NamPower absorbs any cost mismatches within itself.'

\section{Conclusion}

This paper reports on the successful application of the regulatory evaluation framework developed by Brown et al., (2006). Peer reviews provide an effective means for undertaking such evaluations as well as affording unique experiential learning to the peer review participants as they compare and share knowledge and practices in the country being reviewed with their own country contexts.

Effective regulation should lead to cost-effective tariffs, reliable and quality infrastructure service, financial viability of utilities and the attraction of new investments. We find that in the case of Namibia, the regulatory system has encouraged cost effective pricing, although full cost reflectivity is yet to be reached. The pricing regime for generation could be made more efficient and distribution tariffs streamlined. The financial viability of the distribution sector and the attraction of new generation investment do however, present challenges for the long term sustainability and quality of electricity supplies.

\section{Notes}

1. 2001 figures, source Electricity Control Board, Namibia.

2. Source NamPower Annual reports - includes the Scorpion mine which is supplied from the South African grid.

\section{References}

Averch H. and Johnson L. L. (1962). Behaviour of the Firm Under Regulatory Constraint. American Economic Review 52(5): 1053-1069.

Brown A. C., Stern J., et al. (2006). Handbook for Evaluating Infrastructure Regulatory Systems, The World Bank.

Eberhard A., Foster V., et al. (2008). Underpowered: The State of the Power Sector in Africa. Africa Infrastructure Country Diagnostic, World Bank.

Fitch (2009). Namibia Power Corporation (Proprietry) Limited.

Levy B. and Spiller P. T. (1994). The Institutional Foundations of Regulatory Commitment: A Comparative Analysis of Telecommunications Regulation. Journal of Law, Economics, \& Organization 10(2).

Ministry of Mines and Energy (1998). White Paper on Energy Policy: 39.

NamPower (2009). NamPower Investor Update.

Newbery D. (1997). Rate-of-Return Regulation Versus Price Regulation for Public Utilities.

Southern African Power Pool (2009). Overview of the Southern African Power Pool. SADC-SAPPRERA Investors Roundtable. Livingstone, Zambia.

Stern J. (1997). What Makes an Independent Regulator Independent? Business Strategy Review 8(2): 67-74.

Stern J. (2009). The Regulatory and Institutional Dimension of Infrastructure Services. Department of Economics Discussion Paper Series, City University, London.

Stern J. and Cubbin J. (2005). 'Regulatory Effectiveness: The Impact of Regulation and Regulatory Governance Arrangements on Electricity Industry Outcomes.' World Bank Policy Research Working Paper (3536).

Stern J. and Holder S. (1999). Regulatory Governance: Criteria for Assessing the Performance of Regulatory Systems - An Application to Infrastructure Industries in the Developing Countries of Asia. Utilities Policy 8: 33-50.

Received 25 February 2010, revised 18 August 2010 